\title{
The influence of fucoidan on stability, adsorption and electrokinetic properties of $\mathrm{ZnO}$ and $\mathrm{TiO}_{2}$ suspensions
}

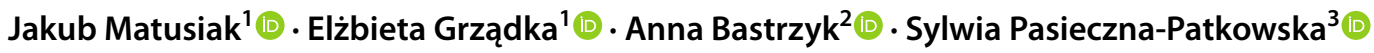

Received: 22 December 2020 / Accepted: 17 February 2021 / Published online: 7 March 2021

(c) The Author(s) 2021

\begin{abstract}
Stabilization of nano-oxide suspensions is a very important process. Nowadays, synthetic polymers are used to increase stability of the colloidal systems. However, this solution is not ecological and incompatible with the principles of green chemistry. Instead of synthetic polymers, their natural counterparts can be used. Herein, we present the use of natural bioactive polysaccharide-fucoidan as a stabilizer of nano-zinc(II) and nano-titanium(IV) oxide suspensions. These two oxides are commercially available and are widely used in the cosmetic and pharmaceutical industries. The turbidimetric studies (Turbiscan Lab) showed that the addition of fucoidan leads to the increase of stability and that the effect depends on the polymer concentration. To fully describe the systems' stability, the adsorption (UV-Vis and FT-IR/PAS) and the electrokinetic properties (zeta potential and surface charge density) were studied. The obtained results indicate that fucoidan adsorbs by the electrostatic and non-electrostatic interactions on the used oxides forming the tight adsorption layer. The following paper thoroughly explains the stabilization mechanism of fucoidan toward the nano-oxide suspensions. Moreover, the presented results could be useful in the preparation of new cosmetic and pharmaceutical products containing nano-oxides.
\end{abstract}

Keywords Turbiscan $\cdot \mathrm{TSI} \cdot \mathrm{ZnO} \cdot \mathrm{TiO}_{2} \cdot$ Nano-oxides

\section{Introduction}

Nanotechnology is one of the most dynamically developing fields of science. Even though this term means very little to an average consumer, it is incredibly profitable from the manufacturers' point of view. Therefore, many technological giants spends billions of USD every year for their R\&D departments. Taking this into account, the experiments on nanoparticles are not only commercially important, but also scientifically. While new products are developed, and their new properties are appreciated, the science behind this is very limited. Nowadays, a great part of cosmetic and pharmaceutical formulations is based on the different nanomaterials (Nohynek et al. 2008; Raj et al. 2012). In the case of colloidal suspensions, which are extensively used in the industry, the main problem is their limited stability. The colloidal suspensions composed of oxide particles and an aqueous medium is susceptible to aggregation, agglomeration and sedimentation (Chabni et al. 2011). To counteract the systems instability, the addition of different substances is used. Among others, the most often, polymers are used to this purpose (Pefferkorn 1995; Pettersson et al. 2000; Farrokhpay 2009). The problem with the use of the synthetic Institute of Chemical Sciences, Maria Curie-Sklodowska University, M. Curie-Sklodowska Sq. 3, 20-031 Lublin, Poland

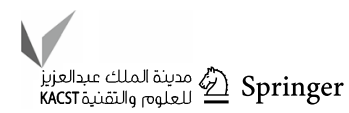


polymers is their limited applicability due to the health concerns. Moreover, in many cases, they are environmentally unfriendly and can cause some negative changes in the ecosystem (Mülhaupt 2013). A solution to this problem is the use of natural macromolecular compounds such as polysaccharides (Rinaudo 2007; Bouyer et al. 2012). The marine polysaccharides obtained from the different kinds of algae and other aquatic species are of a great interest (Laurienzo 2010; Ruocco et al. 2016). Fucoidan is one of the marine polysaccharides that is obtained from the brown algae and other brown seaweeds (Wijesekara et al. 2011). It is an anionic polysaccharide composed of L-fucose rings connected by the glycosidic bond. The negative charge of the polymer chains comes from the presence of the sulfate groups. Moreover, other functional groups such as carboxylic group can be found in the polymer structure $(\mathrm{Li}$ et al. 2008). Fucoidan can be used as a stabilizer of colloidal suspensions (Matusiak et al. 2020). Furthermore, it is used in different formulations due to its bioactive properties (Zayed et al. 2020).

Stabilization of the colloidal systems is a very sophisticated process that depends on many factors (Tadros 2011). The addition of the polymer to the studied system leads to stabilization due to the steric and/or depletion effects (Zhulina et al. 1990). Steric stabilization occurs when the polymer adsorbs on the solid surface. In such case, the formed polymer layer leads to the lower contact between the solid particles, which results in the increase of stability (Tadros 2013). When the used polymer is characterized by an ionic nature, the term steric stabilization changes to the electrosteric one since the new charge factor is present in the system (Fritz et al. 2002). On the other hand, if the polymer does not adsorb on the solid surface, but its chains are located between the solid particles preventing from their aggregation, the depletion stabilization is observed (Semenov and Shvets 2015). Since this process depends on many variables, it requires the comprehensive approach. Therefore, the adsorption of the polymer on the surface of the studies oxides and the electrokinetic studies of the used system are necessary to describe the stabilization mechanisms.

The aim of this study was to investigate stability of two nano-oxides suspensions: $\mathrm{ZnO}$ and $\mathrm{TiO}_{2}$ in the absence and presence of fucoidan. These oxides are commercially used in different cosmetic and pharmaceutical formulations, for example in ointments, creams, pastes, suspensions and lotions (Weir et al. 2012; Kołodziejczak-Radzimska and Jesionowski 2014). There is no information available on stabilization of the oxides used in the cosmetic products using fucoidan as a stabilizer. Therefore, this paper presents new, valuable and detailed information regarding stabilization of the fucoidan $/ \mathrm{ZnO}$ and the fucoidan/ $/ \mathrm{TiO}_{2}$ nanosized suspensions. To describe the stabilization mechanisms, the adsorption and the electrokinetic studies (zeta potential and surface charge density) were carried out. Based on the obtained results, it was established that fucoidan adsorbs on the studies nano-oxides, and strongly influences stability and the electrokinetic properties of the systems. Moreover, using FT-IR/PAS and UV-Vis adsorption studies as well as the electrokinetic one, it was shown that the adsorption of fucoidan is not only electrostatic, but its mechanism can be also considered non-electrostatic. The stability of the studied systems increased with the fucoidan concentration and was higher for the $\mathrm{TiO}_{2}$ suspension. The obtained results represent better perspective on the use of natural polymers as potential green stabilizers of the colloidal systems.

\section{Materials}

Two different nano-sized oxides were used as adsorbents: zinc(II) oxide ( $\mathrm{ZnO}$, zincite, CAS 1314-13-2) and titanium(IV) oxide $\left(\mathrm{TiO}_{2}\right.$, anatase, CAS 1317-70-0). Both nano-oxides are commercially available and were obtained from Alfa Aesar (Thermo Fisher Scientific). They were washed with ultrapure water using the laboratory magnetic stirrer until the conductivity of the supernatants was below $2 \mu \mathrm{S} / \mathrm{cm}$. Then they were dried in a laboratory oven $\left(100^{\circ} \mathrm{C}\right)$ and then they were used in the further experiments. According to the producer information, the size of primary particles was estimated to $40-100 \mathrm{~nm}$ and $32 \mathrm{~nm}$ for $\mathrm{ZnO}$ and $\mathrm{TiO}_{2}$, respectively. The actual size of the particles in suspensions was obtained using the DLS measurements (ZetaSizer ZS90, Malvern). The size distribution is shown as the changes of relative intensity of light scattered by the nanoparticles ( $Y$ axis) versus particle size ( $X$ axis). It equalled $145 \mathrm{~nm}$ for $\mathrm{ZnO}$ and $114 \mathrm{~nm}$ for $\mathrm{TiO}_{2}$ (Fig. 1). The specific surface area was also investigated using the low temperature adsorption-desorption studies (ASAP BET, Micrometrics). Zinc(II) oxide was characterized with lower specific surface

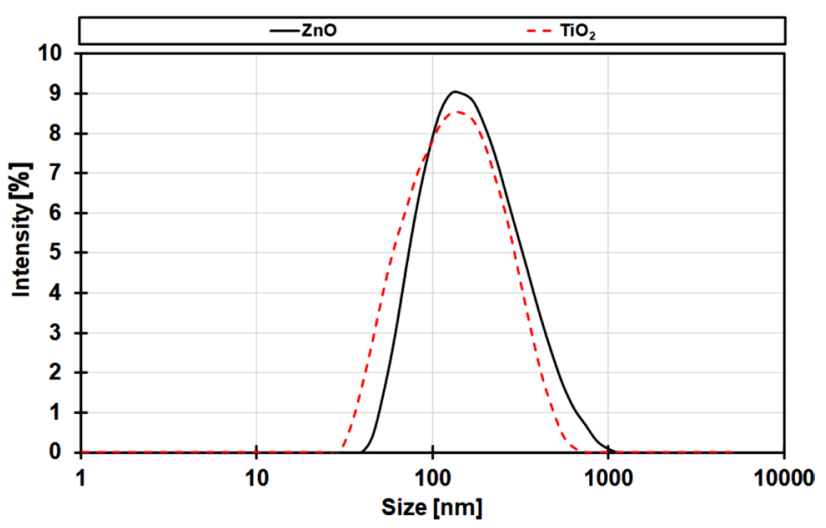

Fig. 1 The particle size distribution of the two used nano-oxides $\left(\mathrm{ZnO}\right.$ and $\mathrm{TiO}_{2}$ ) obtained from DLS measurements 
area $\left(S_{\mathrm{BET}}\right)$ of $13.6 \mathrm{~m}^{2} / \mathrm{g}$, whereas the $S_{\mathrm{BET}}$ of $\mathrm{TiO}_{2}$ equalled $50.3 \mathrm{~m}^{2} / \mathrm{g}$. The purity of the used nano-oxides was confirmed using the X-ray fluorescence spectrometry (Epsilon 5, PANalytical) showing that both contained over 99.2 and $98.6 \%$ of zinc(II) oxide and titanium(IV) oxide, respectively.

Commercially available fucoidan (Carbosynth Ltd., CAS 9072-19-9) was used as an adsorbate. Its molecular weight was estimated using the static light scattering method and equalled $1730 \mathrm{kDa}$. The sulphate content was also investigated. The conducted analysis showed that the polymer chain contained $5.96 \%$ of sulfate groups. Further information regarding the polymer characterization, molecular weight and sulfate content, FT-IR confirmation, altogether with the detailed measurements conditions were published in the previous work (Matusiak et al. 2020).

Other reagents: sodium chloride, sulfuric acid, hydrochloric acid and sodium hydroxide were purchased from $\mathrm{POCH}$ Gliwice (Avantor Performance Materials Poland).

\section{Methods}

\section{Adsorption}

To quantify the adsorption of fucoidan (FD) on the $\mathrm{ZnO}$ and $\mathrm{TiO}_{2}$ surfaces, the colorimetric method was used (Albalasmeh et al. 2013). The adsorption experiments were prepared as follows: to $10 \mathrm{~cm}^{3}$ of the polymer solution with various concentrations (50-500 ppm) containing ultrapure water and sodium chloride as a background electrolyte $(0.01 \mathrm{~mol} /$ $\left.\mathrm{dm}^{3}\right), 0.1 \mathrm{~g}$ of the nano-oxide powder was added. Then $\mathrm{pH}$ was verified, and the sealed flasks were placed in a thermostatic bath with linear shaking $\left(25^{\circ} \mathrm{C}, 120 \mathrm{rpm}\right)$ for $15 \mathrm{~h}$ to achieve the adsorption-desorption equilibrium. Then, the contents of the flasks were transferred to the test tubes and centrifuged twice (4000 rpm) to separate the solid particles from the liquid. The obtained supernatants were used in further adsorption studies. $0.5 \mathrm{~cm}^{3}$ of each supernatant was placed in a glass tubes, then $0.5 \mathrm{~cm}^{3}$ of the ultrapure water and $3 \mathrm{~cm}^{3} 96 \%$ sulfuric acid were added. The mixture was gently mixed and cooled to the room temperature. Then the obtained mixtures were analyzed in UV-Vis spectrophotometer (Cary 100, Varian Instruments) with ultrapure water as a reference. The absorbance was measured at $315 \mathrm{~nm}$. The adsorption values were calculated from the earlier prepared calibration curves. The adsorption measurements were conducted at least in triplicate and the average value was used.

\section{FT-IR/PAS spectroscopy}

Fourier transformed photoacoustic infrared spectra (FT-IR/ PAS) of the examined samples were recorded by means of Bio-Rad Excalibur FT-IR 3000 MX spectrometer over the $4000-400 \mathrm{~cm}^{-1}$ range at room temperature, resolution $4 \mathrm{~cm}^{-1}$, mirror velocity $2.5 \mathrm{kHz}$ and maximum source aperture, using MTEC Model 300 photoacoustic cell. Dry helium was used to purge the photoacoustic cell before data collection. The spectra were normalized by computing the ratio of a sample spectrum to the spectrum of a MTEC carbon black standard. A stainless steel cup (diameter $10 \mathrm{~mm}$ ) was filled with sample (thickness $<6 \mathrm{~mm}$ ) and interferograms of 1024 scans were averaged for the spectrum, providing good signal-to-noise $(\mathrm{S} / \mathrm{N})$ ratio. No smoothing functions were used. All spectral measurements were performed at least in triplicate.

\section{Stability}

Turbiscan LAB (Formulaction) was used to study stability of the prepared suspensions. This device is used for a fast and sensitive identification of the destabilization mechanisms in a controlled temperature conditions. According to the manufacturer, the instrument detects stability evolution at an early stage and also quantifies the global formula alteration with TSI (turbiscan stability index) scale. The principle of the measurement is based on the turbidimetric method. The laser light passing through the studied system is absorbed and/ or reflected and then the signal is collected by the detector. The more detailed description of this method can be found in the previously published work (Grządka et al. 2020). The suspensions were prepared by the addition of $0.005 \mathrm{~g}$ of solid sample to the sodium chloride solution $\left(0.01 \mathrm{~mol} / \mathrm{dm}^{3}\right)$. Afterward, they were treated with the ultrasounds for $30 \mathrm{~s}$ to disperse the solid particles in a liquid medium. Then, the specific amount of fucoidan was added to obtain the desired concentration (100 and $500 \mathrm{ppm}$ ) and $\mathrm{pH}$ of the suspension was checked. The final sample volume equalled $10 \mathrm{~cm}^{3}$. Such sample was placed in the chamber of Turbiscan Lab device. The changes of the studied system stability were recorded for $15 \mathrm{~h}$, every $1 \mathrm{~h}$. The changes in the system's stability were shown as a change of the turbiscan stability index (TSI) values over time. The calculation of the TSI is based on the laser backscattering of the sample and the number of scans (Kang et al. 2011). The TSI values changes from 0 (for the most stable systems) to 100 (for the least stable systems). In other words, the higher the TSI, the lower will be the stability.

\section{Electrokinetic properties}

The zeta potential (ZP) and the surface charge density $(\sigma)$ experiments of the studied systems were also carried out. The zeta potential calculation is based on the electrophoretic mobility of the studied system using the Smoluchowski equation (Sze et al. 2003). The used device was a ZetaSizer Nano ZS90 (Malvern). The samples were prepared by the

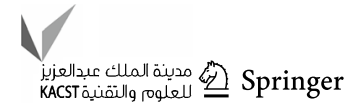


addition of the solid sample $(0.01 \mathrm{~g})$ to $100 \mathrm{~cm}^{3}$ of the solution containing the background electrolyte $(\mathrm{NaCl}, 0.01 \mathrm{~mol} /$ $\mathrm{dm}^{3}$ ) and the polymer. The samples were then treated by the ultrasounds for $3 \mathrm{~min}$. Fucoidan was added after the ultrasound treatment to avoid the polymer chains degradation. $\mathrm{pH}$ of the studied suspensions was adjusted using $\mathrm{HCl}$ $\left(0.01 \mathrm{~mol} \mathrm{dm}^{-3}\right)$ or $\mathrm{NaOH} \mathrm{HCl}\left(0.01 \mathrm{~mol} \mathrm{dm}^{-3}\right)$, respectively. The surface charge density $(\sigma)$ of the nano-oxides before and after the addition of fucoidan was determined by the potentiometric titration. The $\sigma$ was calculated automatically by the Miar_t software developed by Władysław Janusz (commercially unavailable). The suspensions were prepared by the addition of the solid sample (based on the specific surface area of the oxide, so that the available surface of the oxide added to the suspension equalled $20 \mathrm{~m}^{2} / \mathrm{g}$ ) to the $50 \mathrm{~cm}^{3}$ of background electrolyte solution $(\mathrm{NaCl}$, $0.01 \mathrm{~mol} \mathrm{dm}^{-3}$ ) containing the polymer. The suspensions were placed in a thermostated vessel and were titrated with the $\mathrm{NaOH}$ solution $\left(0.1 \mathrm{~mol} \mathrm{dm}^{-3}\right)$ in the $\mathrm{pH}$ range 3-11 (Matusiak and Grządka 2020).

\section{Results and discussion}

The adsorption of the polysaccharides on the solid surface is usually based on the electrostatic interactions between the oppositely charged species. Figure 2 shows the comparison of the adsorption of fucoidan on the surface of the two used nano-oxides: $\mathrm{ZnO}$ and $\mathrm{TiO}_{2}$.

As one can see fucoidan can adsorb on both oxides, but the higher surface coverage is observed in the case of zinc oxide, whereas lower in the case of $\mathrm{TiO}_{2}$. It could be explained by the fact that those two oxides possess different surface properties. Based on the electrokinetic data (further explained in the next parts of the manuscript), the surface of $\mathrm{ZnO}$ in its natural $\mathrm{pH}$ is characterized by the positive charge, whereas the $\mathrm{TiO}_{2}$ surface is neutral or only slightly

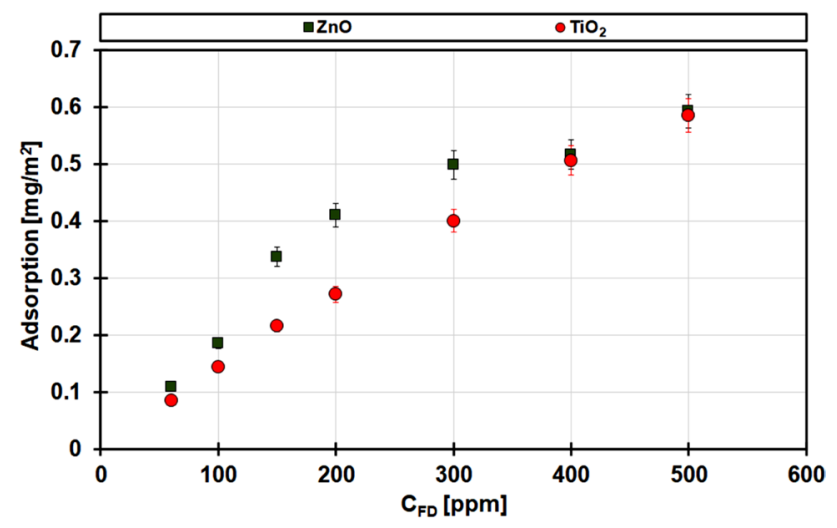

Fig. 2 The comparison of the adsorption of fucoidan on the $\mathrm{ZnO}$ and $\mathrm{TiO}_{2}$ surface; natural $\mathrm{pH}$ : 6.5-7.0 for $\mathrm{ZnO}$ and 6-6.5 for $\mathrm{TiO}_{2}$ positively charged. Because fucoidan is an anionic polysaccharide, its higher adsorption on the surface of $\mathrm{ZnO}$ is governed by the electrostatic interactions between the polymer and the surface. However, in the case of the $\mathrm{FD} / \mathrm{TiO}_{2}$ system, the observed adsorption is lower than in the FD/ZnO system. Considering the fact, that the $\mathrm{TiO}_{2}$ surface in its natural $\mathrm{pH}$ is not charged (or charged in a very small extent) other adsorption mechanisms such as non-electrostatic interactions should be considered. Moreover, the decrease of the adsorption of fucoidan on the surface of these two oxides with increasing $\mathrm{pH}$ also suggests the partial contribution of the electrostatic mechanism in the adsorption of the polysaccharide on the solid surfaces (Fig. 3).

As stated before, the non-electrostatic interactions should not be neglected. Since the titania surface in its natural $\mathrm{pH}$ is barely charged, the most probable mechanism of the fucoidan adsorption except for the electrostatic interactions on the $\mathrm{TiO}_{2}$ surface would be hydrogen bonding. The most likely adsorption mechanism in this system is formation of hydrogen bonds between hydroxyl groups from the fucoidan chain and the hydroxyl ones from the surface of the adsorbent. As one can see, the adsorption barely changes in $\mathrm{pH} 6$ and 7 , but the more significant decrease of the adsorption of fucoidan on $\mathrm{TiO}_{2}$ is observed in $\mathrm{pH} 8$ and 9, where the surface is more negatively charged. The adsorption of fucoidan on the $\mathrm{ZnO}$ and $\mathrm{TiO}_{2}$ surfaces is most likely electrostatic one, whereas the non-electrostatic interactions can also play a significant role. To confirm these findings, the FT-IR/PAS analysis was carried out.

The confirmation of the non-electrostatic adsorption mechanism was found in the FT-IR studies (Fig. 4). In the case of the pre-adsorbed spectra of $\mathrm{ZnO}$ and $\mathrm{TiO}_{2}$, a specific band at $\sim 3690 \mathrm{~cm}^{-1}$ are present. This band is the representation of the isolated $-\mathrm{OH}$ groups that could be found on the solid surface. After the adsorption they disappear, which could confirm the formation of the hydrogen bonds between

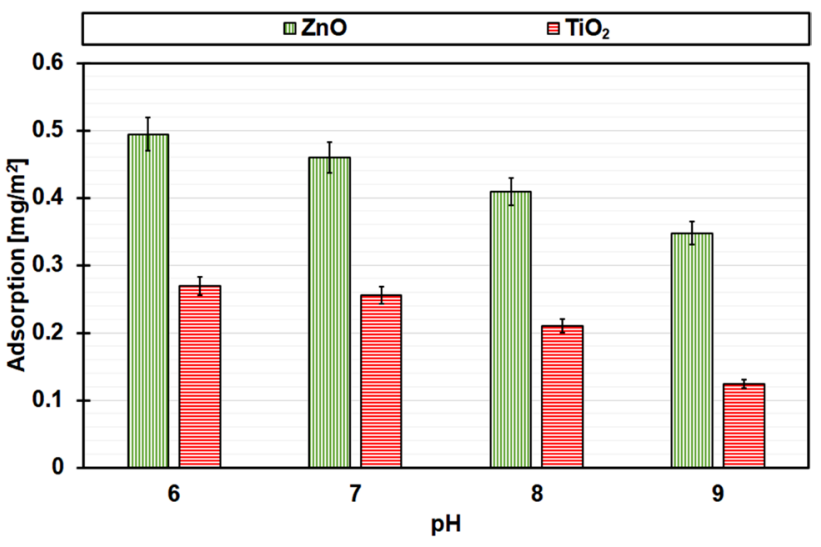

Fig. 3 The influence of $\mathrm{pH}$ on the adsorption of fucoidan (200 ppm) on $\mathrm{ZnO}$ and $\mathrm{TiO}_{2}$ 


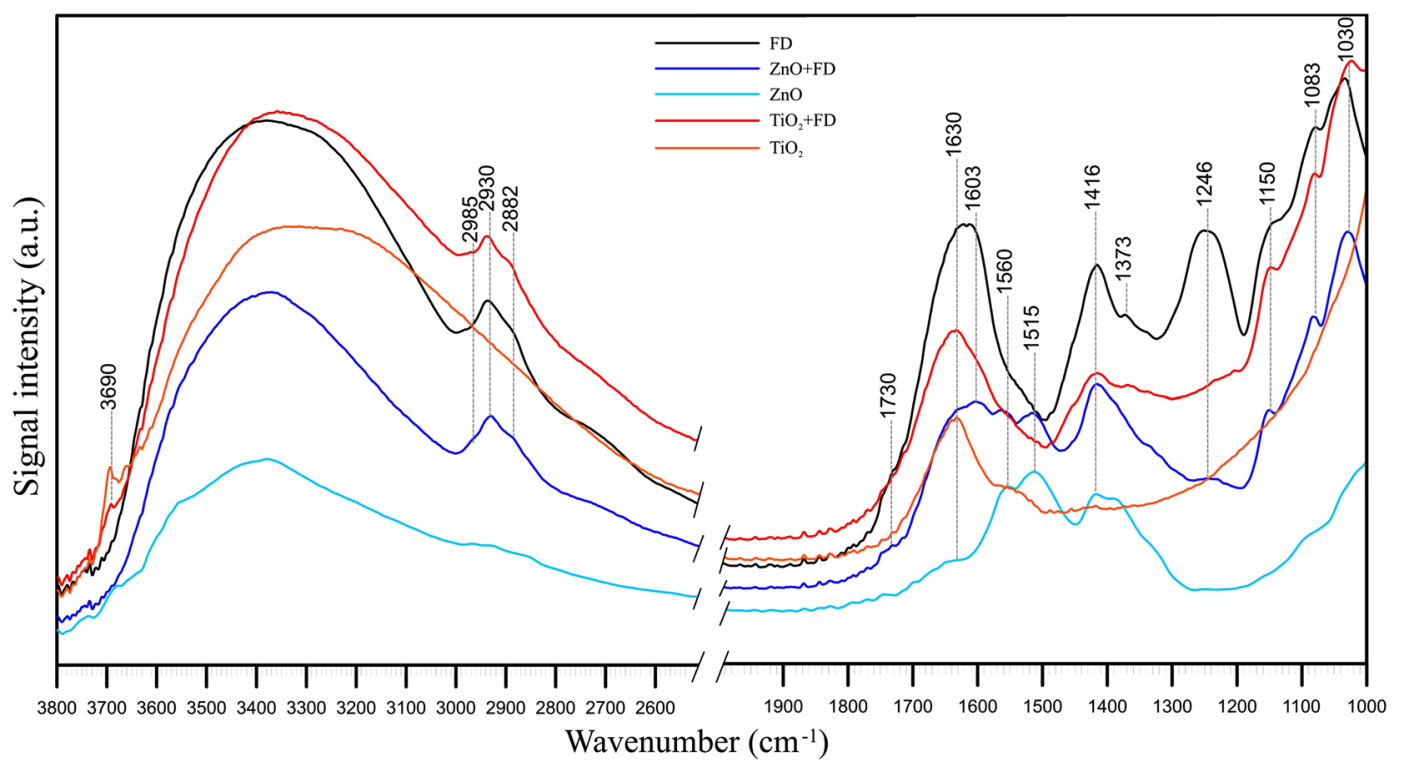

Fig. 4 FT-IR/PAS spectra of pure fucoidan (FD), pre-adsorption $(\mathrm{ZnO}$ and $\mathrm{TiO} 2)$ and post-adsorption $\left(\mathrm{ZnO}+\mathrm{FD}\right.$ and $\left.\mathrm{TiO}{ }_{2}+\mathrm{FD}\right)$

the $\mathrm{ZnO}$ and $\mathrm{TiO}_{2}$ surfaces and the fucoidan chains. Therefore, the combination of the electrostatic interactions and the hydrogen bonding is responsible for the adsorption of FD on the studied oxides. As it was mentioned, Fourier-transform photoacoustic infrared spectroscopy (FT-IR/PAS) was used as a complementary technique for confirmation of fucoidan adsorption on the $\mathrm{ZnO}$ and $\mathrm{TiO}_{2}$ surface. Figure 4 shows the spectra of pure $\mathrm{FD}$, post-adsorption and pre-adsorption (pure $\mathrm{ZnO}$ and $\mathrm{TiO}_{2}$ ). The spectrum of pure FD exhibited a broad band at $\sim 3400 \mathrm{~cm}^{-1}$ and a band at $1630 \mathrm{~cm}^{-1}$ assigned to the $-\mathrm{OH}$ and $\mathrm{H}_{2} \mathrm{O}$ stretching vibrations. The bands within $2985-2882 \mathrm{~cm}^{-1}$ and at $1416 \mathrm{~cm}^{-1}$ are assigned to the $\mathrm{C}-\mathrm{H}$ stretching in pyranoid ring (Chale-Dzul et al. 2015). The band at $\sim 1373 \mathrm{~cm}^{-1}$ is assigned to $\mathrm{C}-\mathrm{H}$ deformation vibrations. The band at $1730 \mathrm{~cm}^{-1}$ is associated with $\mathrm{C}=\mathrm{O}$ stretching, $1603 \mathrm{~cm}^{-1}$ is assigned to the dissociated carboxylic groups $\mathrm{COO}^{-}$stretching. The bands at 1150, 1083 and $1030 \mathrm{~cm}^{-1}$ are responsible for $\mathrm{C}-\mathrm{O}$ stretching and a band at $1246 \mathrm{~cm}^{-1}$ indicates $\mathrm{S}=\mathrm{O}$ asymmetric stretching of sulfate groups (Barbosa et al. 2019). Analyzing the spectra of the $\mathrm{ZnO}$ and $\mathrm{TiO}_{2}$ before and after FD adsorption (Fig. 4), it can be observed that fucoidan adsorbed on the oxides surface. In the spectra of $\mathrm{ZnO} / \mathrm{TiO}_{2}+\mathrm{FD}$, some new bands appear which are absent in the spectra of pure oxides. These are the bands in the range of $\mathrm{CH}$ groups vibration $\left(2985-2882 \mathrm{~cm}^{-1}\right.$ and at $\left.1416 \mathrm{~cm}^{-1}\right)$, the shoulder at $1603 \mathrm{~cm}^{-1}\left(\mathrm{COO}^{-}\right.$stretching) and the bands of $\mathrm{C}-\mathrm{O}$ stretching $\left(1150-1030 \mathrm{~cm}^{-1}\right)$.

The changes of the surface morphology of $\mathrm{ZnO}$ and $\mathrm{TiO}_{2}$ before and after the adsorption were observed on the SEM micrographs (Fig. 5).

As one can see, the adsorption of fucoidan leads to the formation of the larger structures due to the agglomeration of the solid particles by the polymer chains. Before the adsorption, the disordered powder is observed, whereas in the presence of fucoidan, more defined architecture is created.

As previously mentioned, stabilization of the nano-oxide suspensions can be achieved successfully using the addition of macromolecular substances to the system (Matusiak et al. 2020; Grządka and Matusiak 2020). Figure 6a shows the changes in the turbiscan stability index (TSI) of the $\mathrm{TiO}_{2}$ suspension over time before and after the addition of different concentrations of FD.

As one can see, the addition of the polymer causes the decrease of the TSI values which corresponds to the increasing stability. Moreover, stability of the $\mathrm{FD} / \mathrm{TiO}_{2}$ system increases with the increasing concentration of the used polymer. The mechanism of stabilization depends on the fact whether the used polymer adsorbs on the solid surface, or not. Since it was previously established that fucoidan adsorbs on the $\mathrm{TiO}_{2}$ surface the most probable stabilization mechanism is the electrosteric one. In such case, the negatively charged fucoidan chains adsorb on the solid particles of titanium dioxide. During this process, the solid particles are covered by the negatively charged polymer layer. According to the DLVO theory, stability of the colloidal system depends on the sum of the repulsion and attraction forces (Tadros 2010). Such hard spheres with the soft outer layers are stabilized by the electrostatic repulsions. Moreover, because the available adsorption space on the solid surface is limited, the increasing polymer concentration, except for the steric arrangements of the polymer chains, causes the saturation of the surface by the polymer chains. When the fucoidan concentration is low, its chains adsorb in rather flat 
Fig. 5 The surface morphology (SEM) of the oxides before and after the fucoidan adsorption; magnitude $\times 2500$
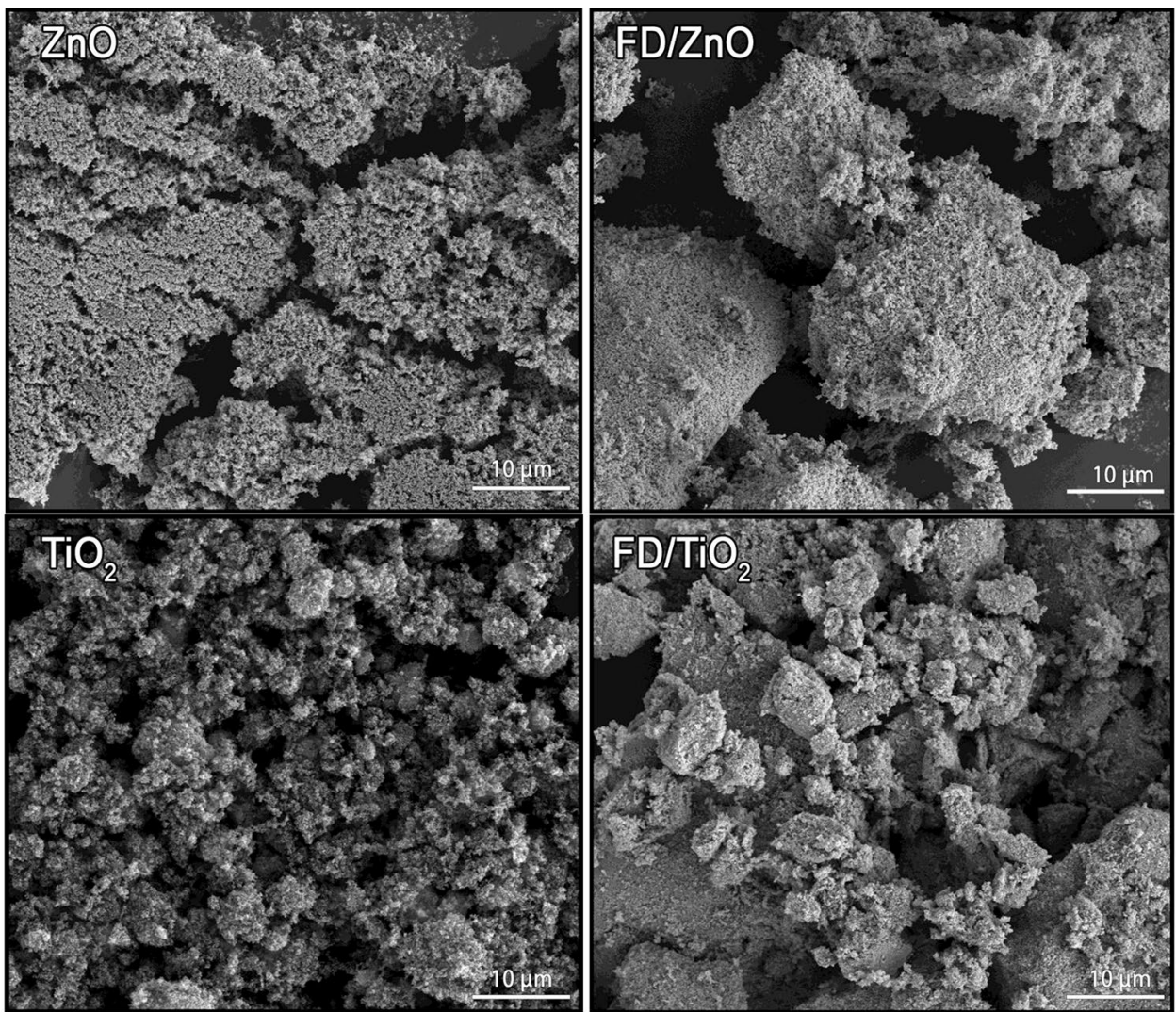

(a)

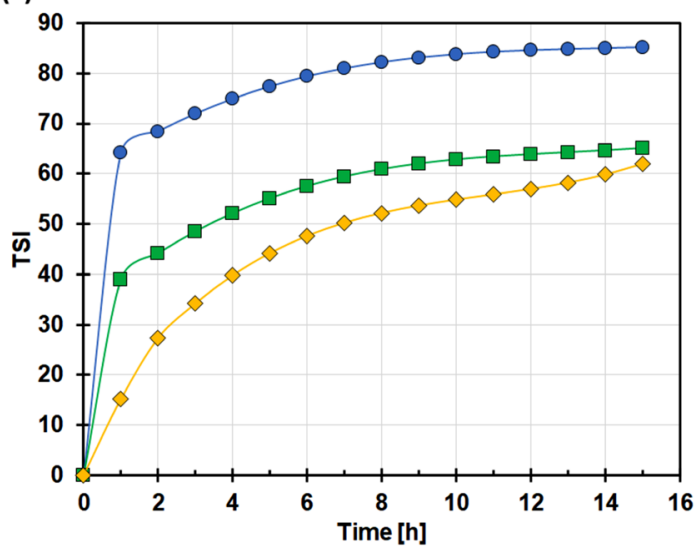

(b)

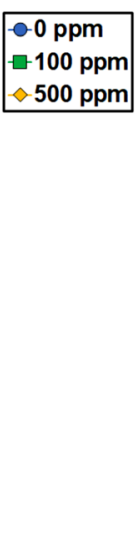

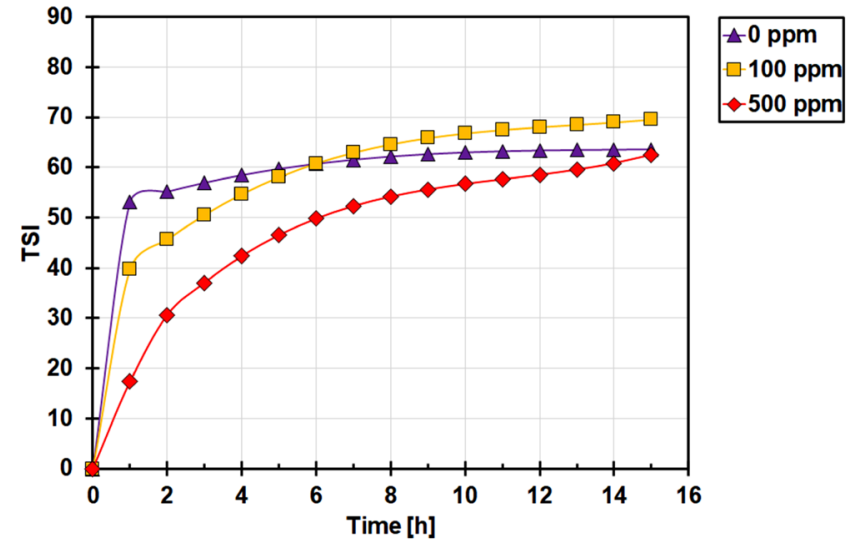

Fig. 6 The changes of TSI over time for the $\mathbf{a} \mathrm{TiO}_{2}$ and $\mathbf{b} \mathrm{ZnO}$ suspensions in the presence of different fucoidan concentrations; $\mathrm{pH}=6.0-6.5$

conformations. When the concentration increases, the rearrangement is observed, and more developed structures rich in loops and tails are formed (Matusiak et al. 2020). When the solid surface is saturated with the polymer chains, the rearrangement is no longer possible. Then the non-adsorbed polymer chains are also located between the FD-covered $\mathrm{TiO}_{2}$ particles. The outcome of their presence between the solid particles can additionally stabilize the system. This phenomenon is called depletion stabilization and it is a consequence of the presence of the non-adsorbed polymer chains located in the bulk of the system (Semenov and Shvets 2015; Kim et al. 2015).

Similar, but less spectacular effect of the fucoidan addition on stability of the $\mathrm{ZnO}$ suspensions was observed (Fig. 6b). First of all, the TSI of pure $\mathrm{ZnO}$ is lower on contrary to the pure $\mathrm{TiO}_{2}$. This observation shows that the $\mathrm{ZnO}$ suspensions are more stable over time without any additives. The addition of $100 \mathrm{ppm}$ of fucoidan to the suspensions 
leads to the small decrease of the TSI in the first $6 \mathrm{~h}$ of the experiments, and rather insignificant increase after that time. This is most likely because $100 \mathrm{ppm}$ of FD is not sufficient to uphold stability of the $\mathrm{ZnO}$ suspensions for the longer period of time. However, the increase of the fucoidan concentration to $500 \mathrm{ppm}$ leads to the increase of stability of the system. As well as in the case of the $\mathrm{FD} / \mathrm{TiO}_{2}$ system, the reason behind this phenomenon is the electrosteric stabilization of the zinc oxide particles.

The electrokinetic properties such as electrokinetic (zeta) potential (ZP) and the surface charge density $(\sigma)$ provide additional information about the adsorption and stability of the studied systems. Two different values characterizing the electrical double layer (EDL) can be obtained based on the analysis of the zeta potential and the surface charge density. These are the isoelectric point $\left(\mathrm{pH}_{\mathrm{IEP}}\right)$ and the point of zero charge $\left(\mathrm{pH}_{\mathrm{pzc}}\right)$. The isoelectric point is $\mathrm{pH}$ where the zeta potential equals zero. In this specific point, the studied colloidal system is the least stable due to the absence of the repulsive forces between the present particles. Another valuable information that can be obtained from the electrokinetic data is the point of zero charge. $\mathrm{The}_{\mathrm{pzc}}$ characterizes $\mathrm{pH}$ in which the number of the positively charged surface groups equals the number of the negatively charged ones. In other words, it is the point where the concentration of the groups bearing the positive charge is the same as the concentration of the negatively charged groups. As one can see, these two values describe different regions of the electrical double layer. $\mathrm{pH}_{\mathrm{IEP}}$ is used to characterize the diffused part of the $\mathrm{EDL}$ (where the zeta potential is measured), whereas $\mathrm{pH}_{\mathrm{pzc}}$ describes the compact part of the EDL that is closer to the particles surface. Figure 7a shows the changes in the zeta potential and the surface charge of $\mathrm{ZnO}$ in the absence and presence of fucoidan.

As one can see, $\mathrm{pH}_{\mathrm{IEP}}$ of $\mathrm{ZnO}$ is between $\mathrm{pH}=8$ and 8.5 and $\mathrm{pH}_{\mathrm{pzc}}$ of this oxide is also close to those values, which agrees with the literature data (Kosmulski 2020). It means that below these points, the surface of $\mathrm{ZnO}$ is positively charged and above them it is negatively charged. The addition of fucoidan to the $\mathrm{ZnO}$ suspension changes the electrokinetic properties of the systems. It can be observed that the PZC shifts toward the lower $\mathrm{pH}$ values, while the IEP is not observed after the addition of the polymer. The adsorption of fucoidan on the $\mathrm{ZnO}$ surface causes the shift of the slipping plane toward the bulk of the solution, which in the end results in the decrease of the zeta potential. Moreover, the higher the concentration, the lower is the zeta potential. Except for the higher adsorption of the polymer, it should be mentioned that with the increasing fucoidan concentration the number of the negatively charged polymer groups also increases. This fact additionally influences the zeta potential value. On the other hand, zeta potential is a valuable tool used to describe stability of the studied colloidal systems. It was established that when the ZP is larger than $\pm 30 \mathrm{mV}$, the studied systems can be considered as stable (Kumar and Dixit 2017). It can be observed that the ZP values after the addition of fucoidan oscillate around $-25 \mathrm{mV}$ for $1 \mathrm{ppm}$ of $\mathrm{FD}$, and $-35 \mathrm{mV}$ for $10 \mathrm{ppm}$ of fucoidan. This fact once again confirms that the addition of FD stabilizes the $\mathrm{ZnO}$ suspensions.

Figure $7 \mathrm{~b}$ shows the changes of the zeta potential and the surface charge in the $\mathrm{FD} / \mathrm{TiO}_{2}$ system. The isoelectric point $\left(\mathrm{pH}_{\mathrm{IEP}}\right)$ of pure $\mathrm{TiO}_{2}$ equals 6 , whereas the point of zero charge $\left(\mathrm{pH}_{\mathrm{pzc}}\right)$ of this oxide is close to 6 . Therefore, the $\mathrm{TiO}_{2}$ surface is positively charged in $\mathrm{pH}<6$ and starts bearing negative charge in $\mathrm{pH}>6$. As it was previously mentioned in the case of this system, the non-electrostatic mechanism of adsorption is possible. The addition of FD to the $\mathrm{TiO}_{2}$ suspension does not shift the PZC and lowers the surface charge only in a very small extent. This also confirms the theory that FD adsorb on the $\mathrm{TiO}_{2}$ surface also by the non-electrostatic interactions. As far as the zeta potential (a)

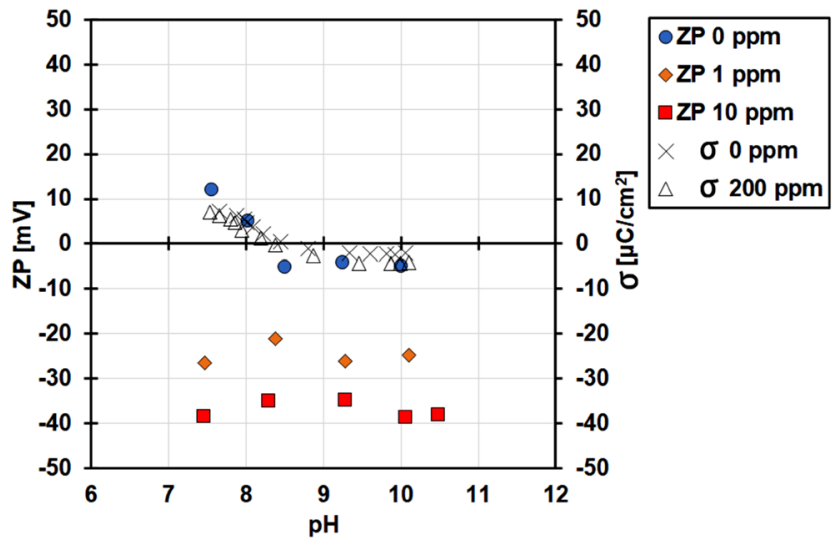

(b)

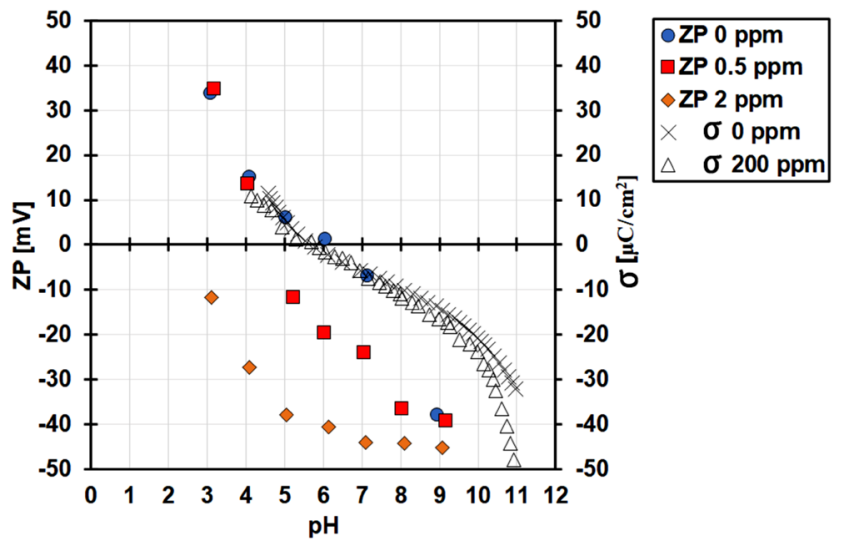

Fig. 7 The changes of the zeta potential ( $\mathrm{ZP})$ and the surface charge density $(\sigma)$ of the $\mathbf{a} \mathrm{ZnO}$ and $\mathbf{b} \mathrm{TiO}_{2}$ suspensions in the presence of fucoidan

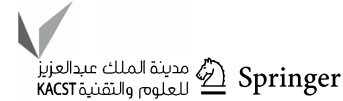


is discussed, the addition of FD leads to the decrease of the ZP of the studied systems. The explanation of this fact is the increasing number of the negatively charged fucoidan groups gathering in the diffused part of the electrical double layer. The higher the concentration, the more groups are delivered, and the consequence is the decrease of the zeta potential.

\section{Conclusions}

Based on the obtained results, it was shown that fucoidan adsorbs on the $\mathrm{ZnO}$ and $\mathrm{TiO}_{2}$ surfaces by the electrostatic and non-electrostatic interactions. It was also established that the addition of fucoidan to the studied suspensions leads to the increased stability due to the combination of the electrosteric and depletion effects. Moreover, stability was higher in the presence of higher fucoidan concentration $(500 \mathrm{ppm})$, but the effect was more spectacular in the case of the $\mathrm{FD} / \mathrm{TiO}_{2}$ system. The addition of fucoidan to the $\mathrm{ZnO}$ and $\mathrm{TiO}_{2}$ suspensions changes their electrokinetic properties. In the case of the zeta potential, the addition of FD leads to the decrease of $\mathrm{ZP}$, which results from the combination of the adsorption of the polymer as well as the presence of the negatively charged groups in the electrical double layer.

The presented results explain the stabilization mechanism of fucoidan toward the nano-oxide suspensions. Furthermore, the obtained data could provide additional information useful in the processes of formulation of new different cosmetic and pharmaceutical products.

Acknowledgements The Authors would like to acknowledge that this research was financially funded by the National Science Centre, Poland [Grant number 2017/27/N/ST4/02259]. Moreover, the work was supported by subsidy from the Polish Ministry of Science and Higher Education for the Faculty of Chemistry of Wroclaw University of Science and Technology.

Author contributions Funding acquisition: JM; Project administration: JM; Conceptualization: JM, EG; Resources: JM, AB; Methodology: JM, EG, AB; Investigation: JM, AB, SP-P; Data curation: JM, Visualization: JM, SP-P; Formal analysis: JM, SP-P; Writing_-Original Draft: JM, EG, SP-P; Writing—Review and Editing: JM, EG.

\section{Declarations}

Conflict of interest On behalf of all authors, the corresponding author states that there is no conflict of interest.

Open Access This article is licensed under a Creative Commons Attribution 4.0 International License, which permits use, sharing, adaptation, distribution and reproduction in any medium or format, as long as you give appropriate credit to the original author(s) and the source, provide a link to the Creative Commons licence, and indicate if changes were made. The images or other third party material in this article are included in the article's Creative Commons licence, unless indicated otherwise in a credit line to the material. If material is not included in the article's Creative Commons licence and your intended use is not permitted by statutory regulation or exceeds the permitted use, you will need to obtain permission directly from the copyright holder. To view a copy of this licence, visit http://creativecommons.org/licenses/by/4.0/.

\section{References}

Albalasmeh AA, Berhe AA, Ghezzehei TA (2013) A new method for rapid determination of carbohydrate and total carbon concentrations using UV spectrophotometry. Carbohydr Polym 97:253-261. https://doi.org/10.1016/j.carbpol.2013.04.072

Barbosa A, Costa Lima S, Reis S (2019) Application of pH-Responsive Fucoidan/Chitosan nanoparticles to improve Ooal quercetin delivery. Molecules 24(2):346. https://doi.org/10.3390/molecules2 4020346

Bouyer E, Mekhloufi G, Rosilio V, Grossiord J-L, Agnely F (2012) Proteins, polysaccharides, and their complexes used as stabilizers for emulsions: alternatives to synthetic surfactants in the pharmaceutical field? Int J Pharm 436:359-378. https://doi.org/10.1016/j. ijpharm.2012.06.052

Chabni M, Bougherra H, Lounici H, Ahmed-Zaïd T, Canselier J-P, Bertrand J (2011) Evaluation of the physical stability of zinc oxide suspensions containing sodium poly (acrylate) and sodium dodecylsulfate. J Disper Sci Technol 32:1786-1798. https://doi. org/10.1080/01932691.2011.616361

Chale-Dzul J, Moo-Puc R, Robledo D, reile-Pelegrín Y (2015) Hepatoprotective effect of the fucoidan from the brown seaweed Turbinaria tricostata. J Appl Phycol 27(5):2123-2135. https://doi. org/10.1007/s10811-014-0429-9

Farrokhpay S (2009) A review of polymeric dispersant stabilisation of titania pigment. Adv Colloid Interface Sci 151:24-32. https://doi. org/10.1016/j.cis.2009.07.004

Fritz G, Schädler V, Willenbacher N, Wagner NJ (2002) Electrosteric stabilization of colloidal dispersions. Langmuir 18:6381-6390. https://doi.org/10.1021/la015734j

Grządka E, Matusiak J (2020) Changes in the CMC/ZrO2 system properties in the presence of hydrocarbon, fluorocarbon and silicone surfactants. J Mol Liq 303:112669. https://doi.org/10.1016/j.molli q.2020.112699

Grządka E, Matusiak J, Bastrzyk A, Polowczyk I (2020) CMC as a stabiliser of metal oxide suspensions. Cellulose 27:2225-2236. https://doi.org/10.1007/s10570-019-02930-y

Kang W, Xu B, Wang Y, Li Y, Shan X, An F, Liu J (2011) Stability mechanism of W/O crude oil emulsion stabilized by polymer and surfactant. Colloid Surface A 384:555-560. https://doi. org/10.1016/j.colsurfa.2011.05.017

Kim S, Hyun K, Moon J-Y, Clasen C, Ahn KH (2015) Depletion stabilization in nanoparticle-polymer suspensions: multi-length-scale analysis of microstructure. Langmuir 31:1892-1900. https://doi. org/10.1021/la504578x

Kołodziejczak-Radzimska A, Jesionowski T (2014) Zinc oxide-from synthesis to application: a review. Materials 7:2833-2881. https ://doi.org/10.3390/ma7042833

Kosmulski M (2020) The pH dependent surface charging and points of zero charge. VIII. Update. Adv Colloid Interface Sci 275:102064. https://doi.org/10.1016/j.cis.2019.102064

Kumar A, Dixit CK (2017) Methods for characterization of nanoparticles. In: Nimesh S, Chandra R, Gupta N (eds) Advances in nanomedicine for the delivery of therapeutic nucleic acids. Elsevier, Amsterdam, pp 43-58. https://doi.org/10.1016/B978-0-08-10055 7-6.00003-1 
Laurienzo P (2010) Marine polysaccharides in pharmaceutical applications: an overview. Mar Drugs 8:2435-2465. https://doi. org/10.3390/md8092435

Li B, Lu F, Wei X, Zhao R (2008) Fucoidan: structure and bioactivity. Molecules 13:1671-1695. https://doi.org/10.3390/molecules1 3081671

Matusiak J, Grządka E (2020) Cationic starch as the effective flocculant of silica in the presence of different surfactants. Sep Purif Technol 234:116132. https://doi.org/10.1016/j.seppur.2019.116132

Matusiak J, Grządka E, Bastrzyk A (2020) Stabilizing properties of fucoidan for the alumina suspension containing the cationic surfactant. Carbohydr Polym 245:116523. https://doi.org/10.1016/j. carbpol.2020.116523

Mülhaupt R (2013) Green polymer chemistry and bio-based plastics: dreams and reality. Macromol Chem Phys 214:159-174. https:// doi.org/10.1002/macp.201200439

Nohynek GJ, Dufour EK, Roberts MS (2008) Nanotechnology, cosmetics and the skin: is there a health risk? Skin Pharmacol Physiol 21:136-149. https://doi.org/10.1159/000131078

Pefferkorn E (1995) The role of polyelectrolytes in the stabilisation and destabilisation of colloids. Adv Colloid Interface Sci 56:33-104. https://doi.org/10.1016/0001-8686(94)00230-A

Pettersson A, Marino G, Pursiheimo A, Rosenholm JB (2000) Electrosteric stabilization of $\mathrm{Al}_{2} \mathrm{O}_{3}, \mathrm{ZrO}_{2}$, and $3 \mathrm{Y}-\mathrm{ZrO}_{2}$ suspensions: effect of dissociation and type of polyelectrolyte. J Colloid Interface Sci 228:73-81. https://doi.org/10.1006/jcis.2000.6939

Raj S, Jose S, Sumod US, Sabitha M (2012) Nanotechnology in cosmetics: opportunities and challenges. J Pharm Bioallied Sci 4:186-193. https://doi.org/10.4103/0975-7406.99016

Rinaudo M (2007) Main properties and current applications of some polysaccharides as biomaterials. Polym Int 57:397-430. https:// doi.org/10.1002/pi.2378

Ruocco N, Costantini S, Guariniello S, Costantini M (2016) Polysaccharides from the marine environment with pharmacological, cosmeceutical and nutraceutical potential. Molecules 21:551. https:// doi.org/10.3390/molecules21050551

Semenov AN, Shvets AA (2015) Theory of colloid depletion stabilization by unattached and adsorbed polymers. Soft Matter 45:88638878. https://doi.org/10.1039/C5SM01365H
Sze A, Erickson D, Ren L, Li D (2003) Zeta-potential measurement using the Smoluchowski equation and the slope of the currenttime relationship in electroosmotic flow. J Colloid Interface Sci 261:402-410. https://doi.org/10.1016/S0021-9797(03)00142-5

Tadros T (2010) General principles of colloid stability and the role of surface forces. In: Tadros TF (ed) Colloid Stability. The Role of Surface Forces, Part I. WILEY-VCH, Weinheim, pp. 1-22. https ://doi.org/10.1002/9783527631193.ch1

Tadros TF (2011) General principles of colloid stability and the role of surface forces. In: Tadros TF (ed) Colloid stability: the role of surface forces-Part I, vol 1. Wiley, Weinheim, pp 1-22. https:// doi.org/10.1002/9783527631070.ch1

Tadros TF (2013) Steric stabilization. In: Tadros TF (ed) Encyclopedia of colloid and interface science. Springer, Heidelberg, pp 1048-1049. https://doi.org/10.1007/978-3-642-20665-8_146

Weir A, Westerhoff P, Fabricius L, Hristovski K, von Goetz N (2012) Titanium dioxide nanoparticles in food and personal care products. Environ Sci Technol 46:2242-2250. https://doi.org/10.1021/ es204168d

Wijesekara I, Pangestuti R, Kim S-K (2011) Biological activities and potential health benefits of sulfated polysaccharides derived from marine algae. Carbohydr Polym 84:14-21. https://doi. org/10.1016/j.carbpol.2010.10.062

Zayed A, El-Aasr M, Ibrahim A-R, Ulber R (2020) Fucoidan characterization: determination of purity and physicochemical and chemical properties. Mar Drugs 18:571. https://doi.org/10.3390/ md18110571

Zhulina EB, Borisov OV, Priamitsyn VA (1990) Theory of steric stabilization of colloid dispersions by grafted polymers. J Colloid Interface Sci 137:495-511. https://doi.org/10.1016/00219797(90)90423-L

Publisher's Note Springer Nature remains neutral with regard to jurisdictional claims in published maps and institutional affiliations. 